\title{
Molecular Engineering of an Alkaline Naphthoquinone Flow Battery
}

\section{Citation}

Tong, Liuchuan, Marc-Antoni Goulet, Daniel P. Tabor, Emily F. Kerr, Diana De Porcellinis, Eric M. Fell, Alán Aspuru-Guzik, Roy G. Gordon, and Michael J. Aziz. 2019. Molecular Engineering of an Alkaline Naphthoquinone Flow Battery 4, no. 8: 1880-1887.

\section{Permanent link}

http://nrs.harvard.edu/urn-3:HUL.InstRepos:42482312

\section{Terms of Use}

This article was downloaded from Harvard University's DASH repository, and is made available under the terms and conditions applicable to Open Access Policy Articles, as set forth at http:// nrs.harvard.edu/urn-3:HUL.InstRepos:dash.current.terms-of-use\#OAP

\section{Share Your Story}

The Harvard community has made this article openly available.

Please share how this access benefits you. Submit a story. 


\section{Molecular Engineering of an Alkaline Naphthoquinone Flow Battery}

Liuchuan Tong, Marc-Antoni Goulet, Daniel P. Tabor, Emily F. Kerr, Diana De Porcellinis, Eric M. Fell, Alán Aspuru-Guzik, Roy G. Gordon,* and Michael J. Aziz*

Dr. Liuchuan Tong, Dr. Daniel P. Tabor, Dr. Alán Aspuru-Guzik, Dr. Roy G. Gordon Department of Chemistry and Chemical Biology, Harvard University, 12 Oxford Street, Cambridge, Massachusetts 02138, USA

Dr. Marc-Antoni Goulet, Dr. Diana De Porcellinis, Eric M. Fell, Dr. Michael J. Aziz Harvard John A. Paulson School of Engineering and Applied Sciences, 29 Oxford Street, Cambridge, Massachusetts 02138, USA

\section{Present Addresses}

Dr. Marc-Antoni Goulet

Form Energy Inc., Somerville, Massachusetts 02143, United States

Dr. Alán Aspuru-Guzik

Department of Chemistry and Department of Computer Science; Vector Institute for Artificial Intelligence, University of Toronto, Toronto, Ontario, M5S 1A1, Canada

*Corresponding authors:

\section{Roy G. Gordon}

Cabot Professor

Dept. of Chemistry and Chemical Biology

Harvard University

12 Oxford Street, MA 02138, USA

Tel: +1 617-495-4017

Fax: +1 617-495-4723

email: Gordon@chemistry.Harvard.edu

\author{
Michael J. Aziz \\ Gene and Tracy Sykes Professor of \\ Materials and Energy Technologies \\ Harvard John A. Paulson School of \\ Engineering and Applied Sciences, Pierce \\ Hall 204a \\ 29 Oxford Street, MA 02138, USA \\ Tel: +1 (617) 495-9884 \\ email: maziz@harvard.edu
}

Keywords: energy storage, flow battery, naphthoquinone, degradation mechanism 
Abstract: Aqueous organic redox flow batteries (AORFBs) have recently gained significant attention as a potential candidate for grid-scale electrical energy storage. Successful implementation of this technology will require redox-active organic molecules with many desired properties. Here we introduce a naphthoquinone dimer, bislawsone, as the redoxactive material in a negative potential electrolyte (negolyte) for an AORFB. This novel dimerization strategy substantially improves the performance of the electrolyte vs. that of the lawsone monomer in terms of solubility, stability, reversible capacity, permeability and cell voltage. An AORFB pairing bislawsone with a ferri/ferrocyanide positive electrolyte delivers an open-circuit voltage of $1.05 \mathrm{~V}$ and cycles at a current density of $300 \mathrm{~mA} / \mathrm{cm}^{2}$ with a negolyte concentration of $2 \mathrm{M}$ electrons in alkaline solution. We determined the degradation mechanism for the naphthoquinone-based electrolyte using chemical analysis, and predict theoretically electrolytes based on naphthoquinones that will be even more stable.

\section{Introduction}

The cost of renewable solar and wind electricity has dropped so much that the greatest barrier to their widespread adoption is their intrinsic intermittency. A cost-effective, long discharge duration electrical energy storage solution could solve the problem of unbalanced supply and demand. Among the various proposed technologies, redox-flow batteries ${ }^{1}$ are particularly attractive for long discharge duration because liquid redox-active electrolytes can be stored in external tanks that are separated from the power generating stack. With this design, energy capacity can be scaled independently of power capacity by simply changing the volume of electrolyte.

Recent years have seen a great deal of research into developing organic redox-active species for aqueous flow battery electrolytes. These redox-active materials are based on earthabundant elements such as carbon, nitrogen, oxygen and sulfur, and usually utilize wellknown redox-active compounds such as quinones, ${ }^{2-9}$ viologens, ${ }^{10-13}$ ferrocenes, ${ }^{14-15}$ aza- 
aromatics, ${ }^{16-18}$ and nitroxide radicals ${ }^{10-11,}{ }^{19}$. Organic-based aqueous flow batteries offer several advantages over vanadium and non-aqueous based flow batteries in cost, scalability and safety. In addition, the use of organic molecules in flow batteries opens a vast chemical space for tailoring the properties of redox-active electrolytes, including solubility, reduction potential, rate capacity, and stability. Within the quinone family, benzoquinones ${ }^{6}$ and anthraquinones ${ }^{2,4,7,9}$ have been explored extensively as redox-active electrolytes in aqueous organic flow batteries. To date, however, there are limited reports on using naphthoquinone as an active electrolyte due not only to stability and solubility concerns but also because naphthoquinone reduction potentials tend to be intermediate between those of benzoquinones and anthraquinones, making them unsuitable for either terminal of an aqueous flow battery. 2hydroxynaphthoquinone, commonly known as lawsone, is a natural product extracted from the leaves of the henna plant and the flower of the water hyacinth, which makes its use or derivatives of it particularly appealing from a cost and scalability perspective. ${ }^{20}$ Lawsone has been explored as a candidate for alkaline flow batteries $;{ }^{21-22}$ however, poor cycling stability has limited further investigation into this class of molecules. It is hypothesized that the C-H position next to the quinone functional group in the molecule is prone to Michael addition, particularly in alkaline media, and subsequent degradation from hydroxide or other nucleophiles during cycling ${ }^{6,23-24}$. Efforts to modify the molecule have been made by installing a carboxyl group onto the open aromatic $\mathrm{C}-\mathrm{H}$ position. Despite the increased solubility of this derivative, capacity utilization, cycling stability, and permeability remain as issues. $^{25}$

Here, we report a naphthoquinone dimer 2,2'-bis(3-hydroxy-1,4-naphthoquinone), or bislawsone, as a high capacity, reversible negolyte material for aqueous organic flow batteries. Bislawsone was constructed by taking advantage of the reactive open site and linking two lawsone units via their 3-position. We demonstrate that this dimerization strategy improves solubility, stability, reduction potential, and permeability without compromising the capacity 
per molecular weight. We also elucidate the degradation mechanism of bislawsone and propose strategies to further stabilize the molecule based on theoretical calculations. We draw important implications for the synthetic strategy and rational design of stable quinone molecules for AORFBs.

\section{Results and Discussion}

Synthesis and physical properties study. Bislawsone was synthesized via a one-step radical dimerization of the natural product lawsone using inexpensive chemicals and solvents (Figure 1A, Figure S1, S2). No further steps were necessary to purify this yellow powder. Its physical and electrochemical properties were evaluated. Cyclic voltammetry of bislawsone in $1 \mathrm{M}$ $\mathrm{KOH}$ showed a reduction potential of $-0.551 \mathrm{~V}$ vs. standard hydrogen electrode (SHE) with a peak separation $(\Delta \mathrm{E})$ of $71 \mathrm{mV}$ for 4 electrons. The reduction potential is $50 \mathrm{mV}$ more negative than that of the lawsone monomer with overlapping peaks for the two subunits (Figure S3A), indicating higher cell voltage, and improved reversibility despite the doubling of the molecular size and the number of electrons transferred. Pairing this electrolyte with potassium ferrocyanide should yield an equilibrium cell potential of $1.05 \mathrm{~V}$ (Figure 1B). Based on the sharpness of the $\mathrm{CV}$ peaks, the two redox centers in the molecule do not appear to interact with each other; this conclusion is also supported by theoretical calculations (Figure 4). The pKa values ( 6.5) for each of the hydroxyl groups in the molecule are indistinguishable by titration and are slightly higher than that of lawsone (Figure 1C, Figure $\mathrm{S} 3 \mathrm{~B}$, Table S1). The two low pKa phenols in bislawsone serve as the solubilizing groups in alkaline solution. To our surprise, the solubility of bislawsone reached 0.56 M (2.24 M electrons or $60.0 \mathrm{Ah} / \mathrm{L})$ in $\mathrm{pH} 14$ solution, as compared to the $0.48 \mathrm{M}(0.96 \mathrm{M}$ electrons) solubility of lawsone in $\mathrm{pH} 14$ solution. The origin of this increased solubility is hypothesized to be from the non-planar nature of the dimer along the 3,3 -single bond. The non-planar 
113 feature may disrupt crystal packing, which would raise the solubility of the whole molecule

114 compared to that of the planar monomer. The increased solubility of the dimer is in contrasted

115 with the usually decreased solubility of many extended polymers compared to their parent

116 monomers. $^{26}$

A

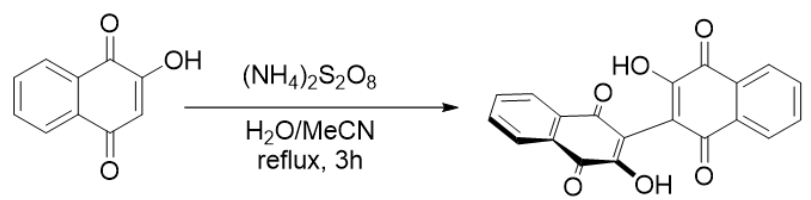

B

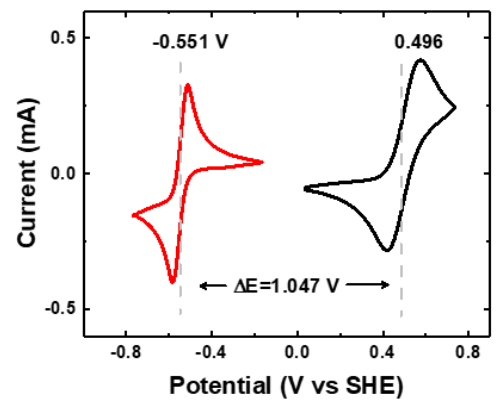

D

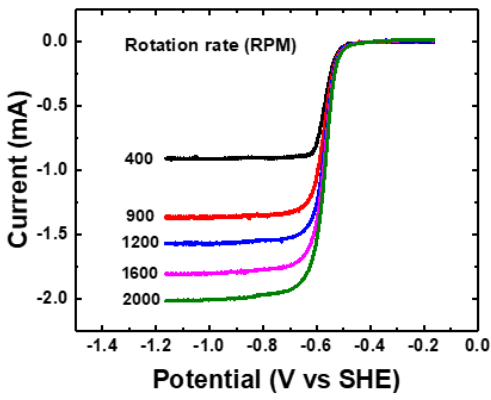

C

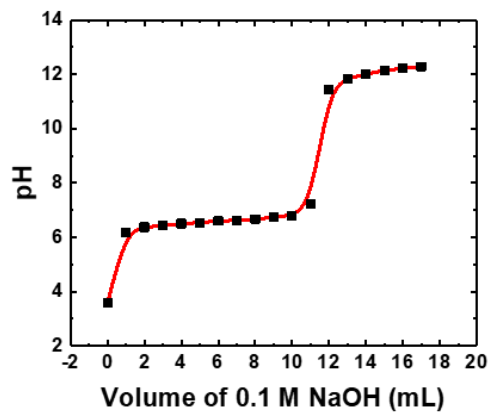

E

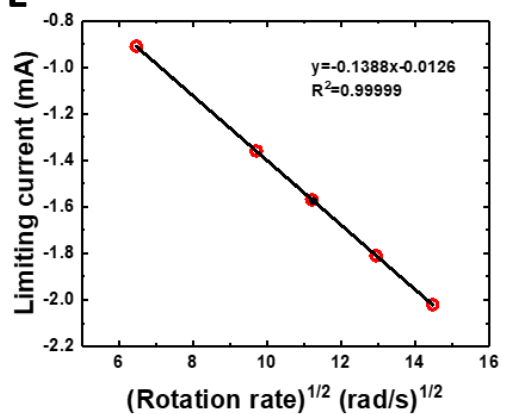

118 Figure 1. Synthesis and physical Characterization of bislawsone. (A) Synthetic scheme of bislawsone. (B) Cyclic voltammograms of $5 \mathrm{mM}$ bislawsone (red), and $10 \mathrm{mM}$ potassium ferrocyanide (black) in $1 \mathrm{M} \mathrm{KOH}$ at a scan rate of $50 \mathrm{mV} / \mathrm{s}$. The redox potential vs $\mathrm{SHE}$ is indicated. (C) Titration of $10 \mathrm{~mL} 0.05 \mathrm{M}$ bislawsone using $0.1 \mathrm{M} \mathrm{NaOH}$ solution. (D) Rotating disk electrode (RDE) measurements of bislawsone using a glassy carbon electrode in $1 \mathrm{M}$ $\mathrm{KOH}$ at 5 rotation rates. (E) Levich plot of limiting current versus square root of rotation rate $\left(\omega^{1 / 2}\right)$

A dimerization strategy, as employed in the case of bislawsone, should offer the

127 advantage of lowered permeability without significantly compromising the diffusivity or

128 viscosity. The diffusion coefficient $(D)$ of bislawsone was determined by rotating disk 
129 electrode measurement and calculated according to the Levich plot of limiting current versus

130 square root of rotation rate to be $4.54 \times 10^{-6} \mathrm{~cm}^{2} / \mathrm{s}$ (Figure 1D, 1E), which is in line with those

131 of most small organic molecules. ${ }^{2,4,6,9,25}$ The viscosity of bislawsone dissolved in $1 \mathrm{M} \mathrm{KOH}$

132 was consistently below $2 \mathrm{cP}$ for concentrations up to the solubility limit (Figure S4), which

133 bodes well for minimizing energy inefficiency due to pumping loss. The crossover rates of

134 bislawsone and lawsone through a Fumasep E-620K cation exchange membrane were

135 measured in a two-compartment rotating cell (Figure S5). The permeability of bislawsone was

136 determined to be $1.19 \times 10^{-11} \mathrm{~cm}^{2} / \mathrm{s}$, which is an order of magnitude lower than the value of

$1371.01 \times 10^{-10} \mathrm{~cm}^{2} / \mathrm{s}$ for lawsone, as expected.

139 Synthesis and physical properties study.We assembled an alkaline flow battery with a

140 positive electrolyte (posolyte) comprising $44 \mathrm{~mL} 0.2 \mathrm{M}$ potassium ferrocyanide and $0.02 \mathrm{M}$

141 potassium ferricyanide and a negative electrolyte (negolyte) comprising $8 \mathrm{~mL} 0.1 \mathrm{M}(0.4 \mathrm{M}$

142 electrons) bislawsone in $1 \mathrm{M} \mathrm{KOH}$ solution (see "Full Cell Measurement" in the supporting

143 information), separated by a Fumasep E620K cation-exchange membrane. This non-

144 fluorinated membrane has been shown to provide very low permeability to ferro/ferricyanide

145 and to anthraquinones. ${ }^{9}$ These solutions were pumped through a flow cell constructed from

146 graphite flow plates and carbon paper electrodes. During charging, the negolyte biquinone

147 was reduced into bihydroquinone while the ferrocyanide was oxidized into ferricyanide. An

148 excess amount of ferrocyanide was used in the cell testing in order to isolate the negolyte as

149 the capacity limiting side. 
A

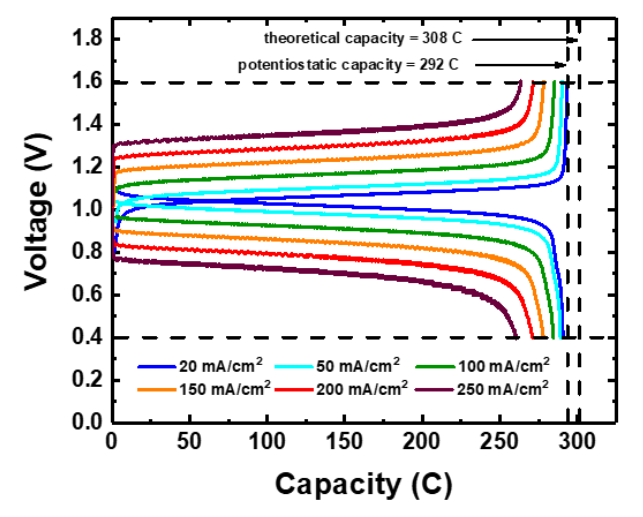

C

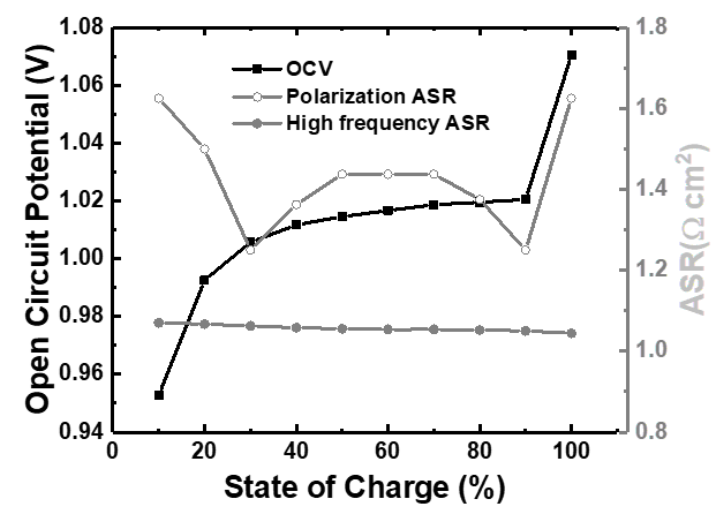

B
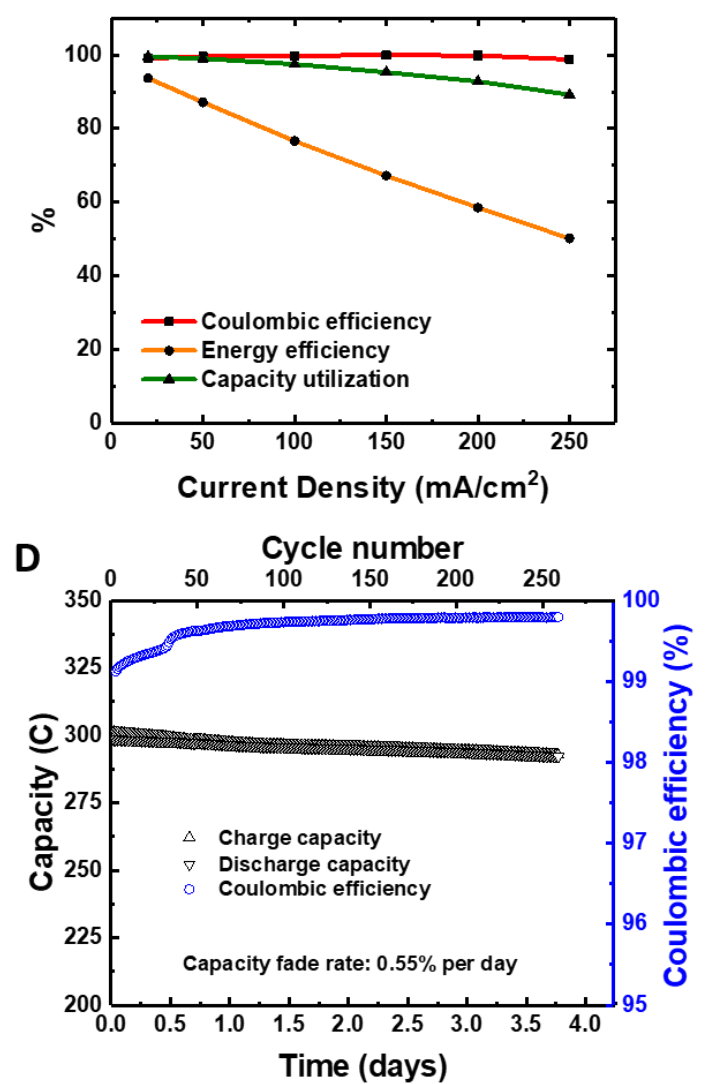

Figure 2. Full cell characterization of low concentration $0.1 \mathrm{M}$ bislawsone. The negolyte comprised $8 \mathrm{~mL}$ of $0.1 \mathrm{M}$ bislawsone in $1 \mathrm{M} \mathrm{KOH}$ while the non-limiting posolyte comprised $45 \mathrm{~mL}$ of $0.2 \mathrm{M}$ potassium ferrocyanide and $0.02 \mathrm{M}$ potassium ferricyanide in $1 \mathrm{M} \mathrm{KOH}$ solution. (A) Galvanostatic charge and discharge curves from 20 to $250 \mathrm{~mA} / \mathrm{cm}^{2}$. The vertical dashed lines indicate the maximum capacity realized with potentiostatic charge and discharge at the voltage cutoffs (1.6 and $0.4 \mathrm{~V}$, respectively), as well as the theoretical capacity. (B) Coulombic efficiency, round-trip energy efficiency, and capacity utilization as a percentage of potentiostatic capacity versus current density. (C) OCV, high-frequency ASR, and polarization ASR versus SOC. (D) Coulombic efficiency (circle) and charge (upward-pointing triangles) and discharge (downward-pointing triangles) capacity versus time and cycle number for a negolyte-limited bislawsone cell. The cell was cycled galvanostatically at $100 \mathrm{~mA} / \mathrm{cm}^{2}$ for 3.8 days. The cell was cycled between 1.4 and $0.5 \mathrm{~V}$, and each half cycle ended with a potentiostatic hold until the magnitude of the current density fell below $2 \mathrm{~mA} / \mathrm{cm}^{2}$.

To confirm that all four electrons in bislawsone can be accessed reversibly, the cell was cycled at different current densities ranging from $20 \mathrm{~mA} / \mathrm{cm}^{2}$ to $250 \mathrm{~mA} / \mathrm{cm}^{2}$ (Figure 2A). For each current density tested, a > 99\% coulombic efficiency and $>90 \%$ capacity utilization were achieved based on the four-electron experimental potentiostatic capacity. A capacity utilization of $97.5 \%$ and round-trip energy efficiency of $77 \%$ was reached at $100 \mathrm{~mA} / \mathrm{cm}^{2}$ 
171 (Figure 2B). The nuclear magnetic resonance (NMR) spectrum of a charged negolyte showed

172 a clean conversion to the fully reduced bislawsone (Figure S6). The high capacity utilization

173 at high current density demonstrated that the dimerization strategy does not negatively affect

174 the kinetics and accessed capacity.

A charging current of $100 \mathrm{~mA} / \mathrm{cm}^{2}$ was applied to charge the cell, and polarization curves were measured at 20,50, and $100 \%$ states of quinone charge (SOC). The open circuit voltage (OCV) is $1.01 \mathrm{~V}$ at $50 \%$ SOC and $1.07 \mathrm{~V}$ at $100 \%$ SOC (Figure 2C), consistent with $\mathrm{CV}$ measurement. The membrane resistance contributed the largest fraction of the overall resistance; it can possibly be decreased in the future by manipulating the electrolyte composition and by decreasing the membrane thickness. The polarization curve (Figure S7)

181 shows no sign of redox kinetic limitations and exhibits a peak galvanic power density 182 exceeding $0.20 \mathrm{~W} \mathrm{~cm}^{-2}$. The viability of a flow battery hinges on the long-term stability of the system. Molecular stability has been a major concern for organic-based flow battery systems as there are many potential degradation pathways for organic molecules. Capacity fade may have both temporal or electrochemical cycling contributions, with the former dominating the lifetimes of

187 the organic molecules that have been carefully studied to date. ${ }^{27}$ To investigate the long-term stability of bislawsone, prolonged galvanostatic cycling of the $0.1 \mathrm{M}$ bislawsone cell was performed at $100 \mathrm{~mA} / \mathrm{cm}^{2}$. In order to avoid temporal variations in accessed capacity and to ensure that $100 \%$ of the redox-active material was cycled, potential holds at $1.4 \mathrm{~V}$ and $0.5 \mathrm{~V}$

191 were applied until the magnitude of the current density fell below $2 \mathrm{~mA} / \mathrm{cm}^{2} .95 \%$ of 192 theoretical capacity was accessed. The 5\% discrepancy may be due to material transfer and residual water in the synthesized bislawsone powder. Over a 3.8-day period of cycling, a $2 \%$

194 capacity loss was observed, which corresponds to a capacity fade rate of $0.55 \%$ per day, or $1950.008 \%$ per cycle. The cell maintained an average of $99.5 \%$ coulombic efficiency, and 196 membrane resistance remained unchanged before and after the cycling. The capacity fade rate 
197 indicates that the lifetime is approximately an order of magnitude longer than that of

198 unprotected lawsone, ${ }^{21-22}$ demonstrating the protective effect of the dimerization strategy 199 employed

200 To investigate the performance at high concentration, a $0.5 \mathrm{M}$ bislawsone cell (2 M 201 electrons, 53.6 Ah/L) was constructed. All four electrons per molecule were accessed at high 202 concentration, as shown in Figure 3A, leading to a 95.5\% capacity utilization even at $300 \mathrm{~mA}$ $203 \mathrm{~cm}^{-2}$ (Figure 3B). This near-quantitative capacity utilization at high current density has not 204 been reported before to our knowledge in alkaline organic flow battery systems, which are 205 usually limited by cell resistance and molecular diffusion. At $400 \mathrm{~mA} / \mathrm{cm}^{2}$, a lower capacity 206 (80.0\%) was accessed because membrane resistance dominated the voltage profile and the cell 207 voltage quickly reached the $1.6 \mathrm{~V}$ and $0.4 \mathrm{~V}$ voltage cutoffs. At $100 \mathrm{~mA} / \mathrm{cm}^{2}, 97.7 \%$ of the 208 capacity was reversibly accessed with a Coulombic efficiency of $99.7 \%$ and round-trip energy 209 efficiency of $79.3 \%$, representing a significant improvement over a lawsone flow battery 210 which had $70 \%$ accessed capacity and $68 \%$ round-trip energy efficiency. ${ }^{25}$ The OCV of the $2110.5 \mathrm{M}$ bislawsone cell displayed typical Nernstian behavior with respect to SOC (Figure S8). 212 A peak galvanic power density of $0.28 \mathrm{~W} / \mathrm{cm}^{2}$ was achieved as determined by the polarization 213 curve at near 100\% SOC (Figure 3C). The power density is mainly limited by high frequency 214 area specific resistance. This is dominated by the membrane resistance (Figure S8), which is 215 above $1 \Omega \cdot \mathrm{cm}^{2}$; it can possibly be decreased in the future by manipulating the electrolyte 216 composition and by using a membrane with better conductivity. 
A

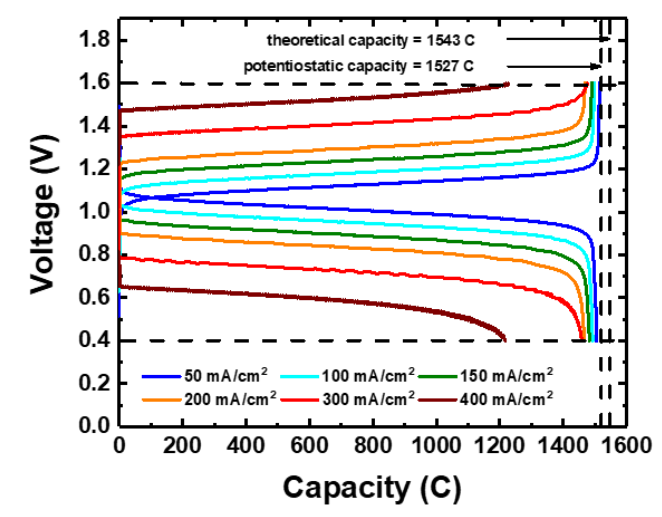

C

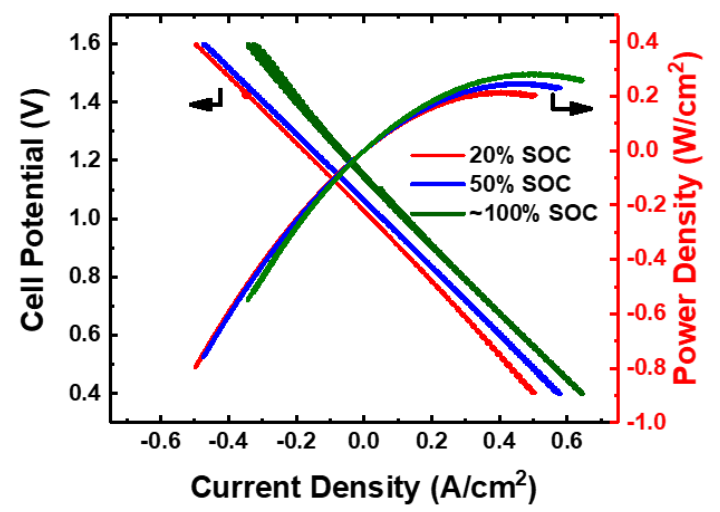

B
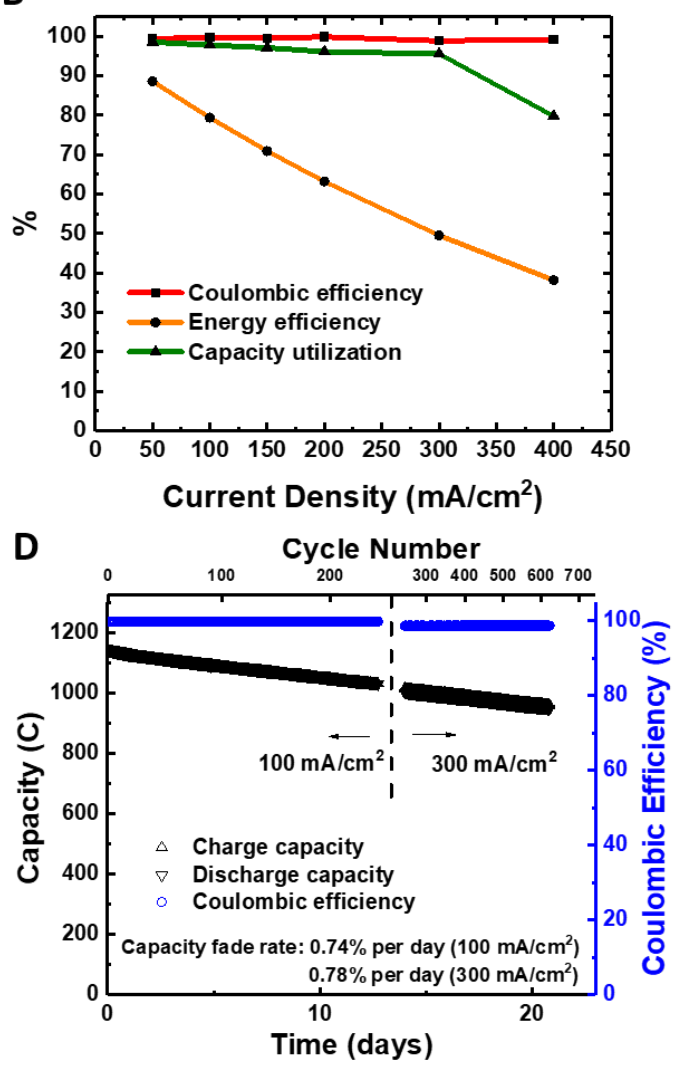

Figure 3. Full cell characterization of high concentration $0.5 \mathrm{M}$ bislawsone. The negolyte comprised $8 \mathrm{~mL}$ of $0.5 \mathrm{M}$ bislawsone in $1 \mathrm{M} \mathrm{KOH}$ while the non-limiting posolyte comprised $95 \mathrm{~mL}$ of $0.3 \mathrm{M}$ potassium ferrocyanide and $0.1 \mathrm{M}$ potassium ferricyanide in $1 \mathrm{M} \mathrm{KOH}$ solution. (A) Galvanostatic charge-discharge voltage profiles from 50 to $400 \mathrm{~mA} / \mathrm{cm}^{2}$. The vertical dashed lines indicate the maximum capacity realized with potentiostatic charge and discharge at the voltage cutoffs (1.6 and $0.4 \mathrm{~V}$, respectively), as well as the theoretical capacity. (B) Coulombic efficiency, round-trip energy efficiency, and capacity utilization as a percentage of potentiostatic capacity versus current density. (C) Cell voltage versus discharge current density at room temperature at 10\%, 30\%, 50\%, 70\%, 90\%, and 100\% SOC. (D) Coulombic efficiency (circles), charge (upward-pointing triangles) and discharge (downward pointing triangles) capacity versus time and cycle number for a negolyte-limited bislawsone cell. The cell was cycled galvanostatically at $100 \mathrm{~mA} / \mathrm{cm}^{2}$ for 12.8 days and then rested for 1.2 days before switching to $300 \mathrm{~mA} / \mathrm{cm}^{2}$ for 6.8 days. The cell was cycled between 1.4 and $0.5 \mathrm{~V}$, and each half cycle ended with a potentiostatic hold until the magnitude of the current density fell below $2 \mathrm{~mA} / \mathrm{cm}^{2}$. The volume of negolyte with same composition used was $6 \mathrm{~mL}$ in (D). $\mathrm{mA} \mathrm{cm}{ }^{-2}$ with potential holds at $1.4 \mathrm{~V}$ for charging and $0.5 \mathrm{~V}$ for discharging until the current

237 density dropped to $2 \mathrm{~mA} / \mathrm{cm}^{2}$ (Figure 3D). $98.3 \%$ of the theoretical capacity was accessed. 
capacity fade of $0.74 \%$ per day, or $0.038 \%$ per cycle. Because an excess amount of posolyte

240 ferrocyanide and ferricyanide were used in the cycling, we attribute the slow capacity fade to

241 the bislawsone negolyte. The per cycle capacity fade in the high concentration cell was

242 superficially higher compared to low concentration cell due to longer per cycle cycling time 243 in high concentration cell. The per day capacity fade rate is similar to that of low 244 concentration cell ( $0.74 \%$ vs $0.55 \%$ per day), indicating that the stability of bislawsone is time 245 dependent rather than cycle dependent.

Encouraged by our high capacity utilization at high current density, we cycled the 0.5

$\mathrm{M}$ bislawsone cell at a higher current density of $300 \mathrm{~mA} / \mathrm{cm}^{2}$. The cell maintained high capacity rate and stable charging/discharging plateau during the 6.8 days of continuous 249 cycling with $98.8 \%$ coulombic efficiency. The cell lost $5.3 \%$ of its capacity, which 250 corresponds to $0.78 \%$ loss per day. This rate is almost identical to the $0.74 \%$ /day loss rate 251 when cycled at $100 \mathrm{~mA} / \mathrm{cm}^{2}$, demonstrating that bislawsone can be cycled at high current 252 density under alkaline conditions without compromising its stability.

Investigation and potential mitigation of chemical degradation. Different strategies have been made in the field to synthesize more stable derivatives based on various redox-active scaffolds. However, the chemical space available for organic molecules is huge. Therefore, it is important to understand how a scaffold molecule degrades in order to rationally design the next generation of molecules with better performance. Despite the fact that bislawsone can inhibit Michael-addition decomposition pathway as compared to lawsone, capacity loss in our 260 system was still observed. We have recently elucidated the molecular degradation mechanism 261 of anthraquinones in flow batteries using 2,6-dihydroxyanthraquinone as a model system. ${ }^{28}$ 262 We therefore studied the degradation of naphthoquinones using bislawsone as a model system. 263 A sample was taken from the above cycled discharged $0.5 \mathrm{M}$ cell and subjected to NMR 264 analysis. One major side product was observed which accounts for $14.2 \%$ of total NMR active 
material (Figure S9). High-resolution liquid chromatography mass spectrometry (LC-MS) analysis found only one major side product with the mass to charge ratio of 347.0559 in negative ionization mode (Figure S10). Back calculation of the neutral mass gives $\mathrm{C}_{20} \mathrm{H}_{12} \mathrm{O}_{6}$ as the molecular formula, which coincides in mass with a partial (2-electron) reduction of bislawsone starting material $\mathrm{C}_{20} \mathrm{H}_{10} \mathrm{O}_{6}$.

In order to elucidate the chemical structure, the degradation product was isolated by 271 preparative-scale high performance liquid chromatography (pHPLC, Figure S11). ${ }^{1} \mathrm{H}, 13 \mathrm{C}$, 272 and 2D NMR analysis on the purified degradation product showed the asymmetry between 273 two monomer units, and the presence of two aliphatic proton peaks with doublet splitting 274 patterns (Figure S12-S14) indicated a disruption in the conjugated system. Together, the 275 NMR and LC-MS analyses are consistent with the structure where the bond between C2 and $276 \mathrm{C} 3$ of the bislawsone is reduced to a carbon-carbon single bond, locking the quinone unit into 277 a di-ketone molecule, 2,3-dihydrobislawsone 4 (Figure $\mathbf{4 A}$, type 1 tautomerization). 278 Electrochemical reduction of a ketone into an alcohol and re-oxidation of the alcohol back to 279 the ketone have high overpotentials and usually require a metal or organic catalyst ${ }^{29-32}$; 280 therefore this side product should generally be considered as redox-inactive in a catalyst-free 281 flow battery system using a carbon-based electrode. Because the similar degradation rate 282 suggests a concentration and rate-independent degradation mechanism, the production of 2,3283 dihydrobislawsone is not due to the direct reduction or oxidization by the electrode, but rather 284 by the enol-ketone tautomerization of the partially reduced quinone-hydroquinone molecule, 285 which is a process governed by kinetics and thermal equilibrium. The degradation of 286 bislawsone into 2,3-dihydrobislawsone may be a general degradation mechanism for 287 naphthoquinones. This conclusion is backed by some earlier studies, ${ }^{33-34}$ which documented 288 the tautomerization of reduced naphthoquinone. While this tautomerization was observed in 289 many different naphthoquinone derivatives in earlier studies, the equilibrium and kinetics 290 were heavily influenced by the substitution groups on the naphthoquinone ring. In this work, 
the 2,3-dihydrobislawsone did not tautomerize back to the half-reduced hydroquinone form $\mathbf{2}$,

292 as the isolated 2,3-dihydrobislawsone was stable in air and alkaline solution. Given this general phenomenon, we expect that the tautomerization should also occur for the fully reduced bislawsone 3 at a different rate (Figure 4A, type 2), that can eventually result in a 4electron reduction 2,2`3,3`-tetrahydrobislawsone form $\mathbf{6}$ (tetra-ketone instead of bi-quinone) that is completely redox inactive). Indeed, careful LC-MS analysis of a discharged sample also found a molecule at a much lower concentration with an atomic mass that corresponds to a 4-electron reduction product after cycling (Figure S15). This molecule cannot be fully reduced bislawsone 3 because the sample was taken at the fully discharged state and exposed to air prior to analysis, and therefore is expected to be the redox-inactive tetra-ketone form.

A

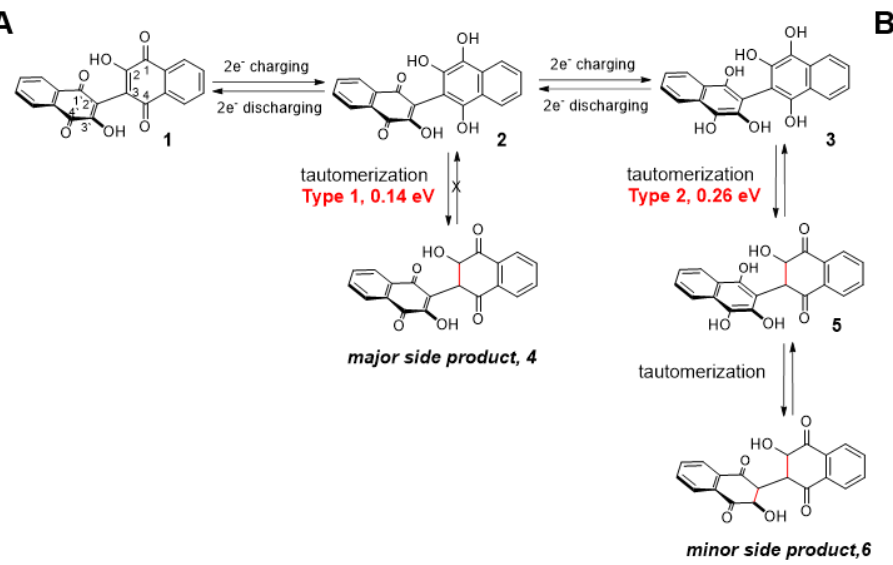

B

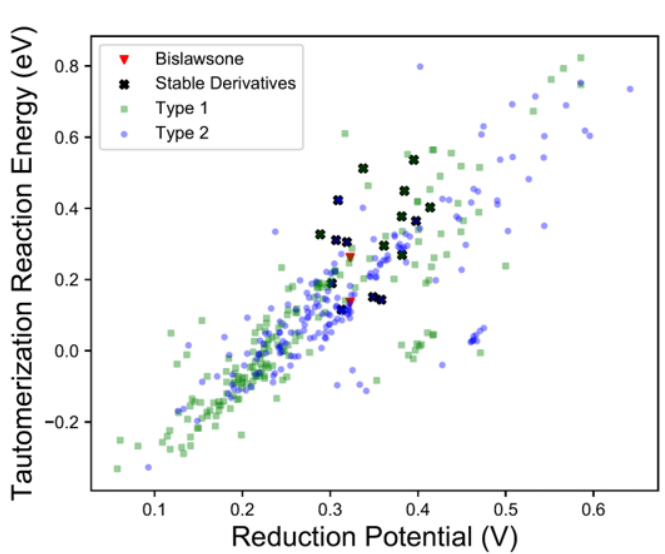

Figure 4. Decomposition study and theoretical calculations. (A) Scheme of decomposition pathway. The red text shows the calculated reaction energies of the reduced forms tautomerizing as calculated at the B3LYP/6-311+G(d,p) (PCM) level of theory. (B) Calculated tautomerization reaction energies plotted against calculated reduction potential of the couple. Type 1 and Type 2 refer to the nature of the intermediate: a "half-reduced" molecule (Type 1) or a fully reduced molecule (Type 2). Bislawsone is labeled with red triangle and 8 stable derivatives within $0.1 \mathrm{~V}$ of bislawsone reduction potential are labeled with black squares.

Based on the structure of degradation product, the degradation of bislawsone into the di-ketone form 4 should disrupt only half of the redox activity, as the other lawsone monomer 
capacity was lost in 21 days of cycling. There are several possibilities to account for the $7.7 \%$

315 difference. First, once reduced naphthoquinone 2 tautomerized into diketone form 4, the 2hydroxy group changed from a low-pKa phenol group into a high-pKa alcohol group, and would stay protonated in alkaline solution. Therefore, the solubility of 2,3-dihydrobislawsone molecule is expected to drop drastically and precipitate out of the solution, making it practically redox-inactive. Precipitate was indeed observed in electrolyte that has been cycled 320 for a long-time. Second, the tetra-ketone form, 2,2`,3,3`-tetrahydrobislawsone 6, accounts for $3211 \%$ of the degradation product as detected by LC-MS, but its concentration is too low to be 322 detected in NMR, and is expected to have even lower solubility due to the transformation of two solubilizing phenol groups into two alcohol groups. Other minor degradation products or NMR silent species and cell leakage may also contribute to the remaining capacity fade.

The equilibrium of hydroquinone-diketone is heavily influenced by the substituents on the naphthoquinone core; therefore, this presents an opportunity for a next generation naphthoquinone with a rationally designed substituent group. We have calculated (see the "Theoretical Calculation" section in Supporting Information) the stability and reduction potentials of 637 lawsone redox couples, which include 193 bislawsone derivatives. Figure

330 4B shows the correlation between the tautomer reaction energies and the predicted standard reduction potentials of redox couples. In general, lower reduction potentials are more likely to

332 be subject to tautomerization than higher reduction potentials. Interestingly, despite the fact 333 that the predicted standard reduction potentials of each of the two reductions of bislawsone 334 are within $0.01 \mathrm{~V}$ of each other, the "type 1 " decomposition is more thermodynamically 335 favored than the "type 2" decomposition. Of these, we predict that 8 bislawsone derivatives with reduction potentials within 0.1

$337 \mathrm{~V}$ of bislawsone potentially have higher stability than bislawsone (Figure S16). One common 338 motif in these stabilized molecules are oxy-alkyl substitutions, which have previously been 339 shown to stabilize anthraquinone molecules against other decomposition mechanisms. ${ }^{35}$ Our 
calculations also indicate that the increased stability of bislawsone can be at least partially

341 attributed to its protection against a tautomerization reaction relative to lawsone. Efforts to synthesize a more stable naphthoquinone are underway.

\section{Conclusion}

In summary, we demonstrate that dimerization is a promising synthetic strategy to improve the performance of quinone-based flow batteries. The bislawsone flow battery reported in this work delivered a high negolyte volumetric capacity, theoretically $53.6 \mathrm{Ah} / \mathrm{L}$ (2 M electrons), with peak power density of $0.28 \mathrm{~W} / \mathrm{cm}^{2}$. It reversibly accessed $>95.5 \%$ of theoretical capacity at a current density of $300 \mathrm{~mA} / \mathrm{cm}^{2}$ with significantly improved permeability and stability, making naphthoquinone a more practical redox-active negolyte in AORFBs. We identified tautomerization of the reduced naphthoquinone to the redox-inactive ketone form as a degradation mechanism of naphthoquinone in flow batteries. This mechanistic insight allowed us to propose more stable naphthoquinones and rationally design next generation organics for AORFB which could accelerate the use of wind and photovoltaic electricity.

\section{Author Contributions}

358 L.T. conceived the idea, developed the synthesis, and performed molecular characterization. 359 E.M.F. and L.T. performed rotating disk electrode characterization. E.F.K. performed 360 additional synthesis and measured solubility and viscosity. D.D.P performed permeability measurements. D.P.T. developed the molecular library and performed the theoretical stability calculations. Cell performance and electrolyte analysis were performed by L.T. and M.-A.G. The chemical degradation study was performed by L.T. The manuscript was drafted by L.T. and D.P.T. and revised by all authors. R.G.G. and M.J.A. supervised the experimental research and A.A.-G. supervised the theoretical research.

\section{Acknowledgements}

This work was supported in part by the following organizations: the U.S. Department of Energy Contract No. DE-AC05-76RL01830 through PNNL Subcontract No. 428977; Innovation Fund Denmark via the Grand Solutions project "ORBATS" file no. 7046-00018B; and the Massachusetts Clean Energy Technology Center. The authors thank Dr. David Kwabi and Shijian Jin for assistance and helpful discussions on experimental techniques. 


\section{References}

376

377

378

379

380

381

382

383

384

385

386

387

388

389

390

391

392

393

394

395

396

397

398

399

400

401

402

403

404

405

406

407

408

409

410

411

412

413

414

415

416

417

418

419

420

421

1. Dunn, B.; Kamath, H.; Tarascon, J.-M., Electrical Energy Storage for the Grid: A Battery of Choices. Science 2011, 334 (6058), 928.

2. Huskinson, B., Marshak, M. P., Suh, C., Er, S., Gerhardt, M. R., Galvin, C. J., Chen, X., Aspuru-Guzik, A., Gordon, R. G., Aziz, M. J., A metal-free organic-inorganic aqueous flow battery. Nature 2014, 505 (7482), 195.

3. Yang, B., Hoober-Burkhardt, L., Wang, F., Surya Prakash, G. K., Narayanan, S. R., An inexpensive aqueous flow battery for large-scale electrical energy storage based on watersoluble organic redox couples. J. Electrochem. Soc. 2014, 161, A1371.

4. Lin, K.; Chen, Q.; Gerhardt, M. R.; Tong, L.; Kim, S. B.; Eisenach, L.; Valle, A. W.; Hardee, D.; Gordon, R. G.; Aziz, M. J.; Marshak, M. P., Alkaline quinone flow battery. Science 2015, 349 (6255), 1529.

5. Yang, B.; Hoober-Burkhardt, L.; Krishnamoorthy, S.; Murali, A.; Prakash, G. K. S.; Narayanan, S. R., High-Performance Aqueous Organic Flow Battery with Quinone-Based Redox Couples at Both Electrodes. J. Electrochem. Soc. 2016, 163 (7), A1442.

6. Yang, Z.; Tong, L.; Tabor, D. P.; Beh, E. S.; Goulet, M.-A.; De Porcellinis, D.; Aspuru-Guzik, A.; Gordon, R. G.; Aziz, M. J., Alkaline Benzoquinone Aqueous Flow Battery for Large-Scale Storage of Electrical Energy. Adv. Energy Mater. 2017, 1702056.

7. Gerhardt, M. R.; Tong, L.; Gómez-Bombarelli, R.; Chen, Q.; Marshak, M. P.; Galvin, C. J.; Aspuru-Guzik, A.; Gordon, R. G.; Aziz, M. J., Anthraquinone Derivatives in Aqueous Flow Batteries. Adv. Energy Mater. 2017, 7 (8), 1601488.

8. Cao, J.; Tao, M.; Chen, H.; Xu, J.; Chen, Z., A highly reversible anthraquinone-based anolyte for alkaline aqueous redox flow batteries. J. Power Sources 2018, 386, 40.

9. Kwabi, D. G.; Lin, K.; Ji, Y.; Kerr, E. F.; Goulet, M.-A.; De Porcellinis, D.; Tabor, D. P.; Pollack, D. A.; Aspuru-Guzik, A.; Gordon, R. G.; Aziz, M. J., Alkaline quinone flow battery with long lifetime at $\mathrm{pH}$ 12. Joule 2018, 2, 1907.

10. Liu, T.; Wei, X.; Nie, Z.; Sprenkle, V.; Wang, W., A Total Organic Aqueous Redox Flow Battery Employing a Low Cost and Sustainable Methyl Viologen Anolyte and 4-HOTEMPO Catholyte. Adv. Energy Mater. 2015, 6 (3), 1501449.

11. Janoschka, T.; Morgenstern, S.; Hiller, H.; Friebe, C.; Wolkersdorfer, K.; Hauptler, B.; Hager, M. D.; Schubert, U. S., Synthesis and characterization of TEMPO- and viologenpolymers for water-based redox-flow batteries. Polym. Chem 2015, 6 (45), 7801.

12. DeBruler, C., Hu, B., Moss, J., Liu, X., Luo, J., Sun, Y., Liu, T. L., Designer twoelectron storage viologen anolyte materials for neutral aqueous organic redox flow batteries. Chem 2017, 3, 1 .

13. Janoschka, T.; Martin, N.; Hager, M. D.; Schubert, U. S., An aqueous redox-flow battery with high capacity and power: the TEMPTMA/MV system. Angew. Chem. Int. Ed. 2016, 55 (46), 14427.

14. Beh, E. S., De Porcellinis, D., Gracia, R. L., Xia, K. T., Gordon, R. G., Aziz, M. J., A neutral $\mathrm{pH}$ aqueous organic-organometallic redox flow battery with extremely high capacity retention. ACS Energy Lett. 2017, 2 (3), 639.

15. Hu, B.; DeBruler, C.; Rhodes, Z.; Liu, T. L., Long-cycling aqueous organic redox flow battery (AORFB) toward sustainable and safe energy storage. J. Am. Chem. Soc. 2017, 139 (3), 1207.

16. Lin, K., Gómez-Bombarelli, R., Beh, E. S., Tong, L., Chen, Q., Valle, A., AspuruGuzik, A., Aziz, M. J., Gordon, R. G., A redox-flow battery with an alloxazine-based organic electrolyte. Nat. Energy 2016, 1 (9), 16102. 

based on flavin mononucleotide. Nat. Comm. 2016, 7, 13230. Wang, W., A biomimetic high-capacity phenazine-based anolyte for aqueous organic redox flow batteries. Nat. Energy 2018, 3 (6), 508.

19. Winsberg, J.; Muench, S.; Hagemann, T.; Morgenstern, S.; Janoschka, T.; Billing, M.; Schacher, F. H.; Hauffman, G.; Gohy, J.-F.; Hoeppener, S.; Hager, M. D.; Schubert, U. S., Polymer/zinc hybrid-flow battery using block copolymer micelles featuring a TEMPO corona as catholyte. Polym. Chem. 2016, 7 (9), 1711.

20. Dweck, A. C., Natural ingredients for colouring and styling. Int. J. Cosmet. Sci. 2002, 24 (5), 287.

21. Wedege, K.; Drazevic, E.; Konya, D.; Bentien, A., Organic Redox Species in Aqueous Flow Batteries: Redox Potentials, Chemical Stability and Solubility. Sci. Rep. 2016, 6, 39101. 22. Hu, P.; Lan, H.; Wang, X.; Yang, Y.; Liu, X.; Wang, H.; Guo, L., Renewablelawsone-based sustainable and high-voltage aqueous flow battery. Energy Storage Mater. 2018.

23. Hoober-Burkhardt, L.; Krishnamoorthy, S.; Yang, B.; Murali, A.; Nirmalchandar, A.; Prakash, G. K. S.; Narayanan, S. R., A New Michael-Reaction-Resistant Benzoquinone for Aqueous Organic Redox Flow Batteries. J. Electrochem. Soc. 2017, 164 (4), A600.

24. Tabor, D. P.; Gómez-Bombarelli, R.; Tong, L.; Gordon, R. G.; Aziz, M. J.; AspuruGuzik, A., Mapping the frontiers of quinone stability in aqueous media: implications for organic aqueous redox flow batteries. J. Mater. Chem. A 2019, 7 (20), 12833.

25. Wang, C.; Yang, Z.; Wang, Y.; Zhao, P.; Yan, W.; Zhu, G.; Ma, L.; Yu, B.; Wang, L.; Li, G.; Liu, J.; Jin, Z., High-Performance Alkaline Organic Redox Flow Batteries Based on 2Hydroxy-3-carboxy-1,4-naphthoquinone. ACS Energy Lett. 2018, 3 (10), 2404.

26. Miller-Chou, B. A.; Koenig, J. L., A review of polymer dissolution. Prog. Polym. Sci. 2003, 28 (8), 1223.

27. Goulet, M.-A.; Aziz, M. J., Flow Battery Molecular Reactant Stability Determined by Symmetric Cell Cycling Methods. J. Electrochem. Soc. 2018, 165 (7), A1466. 28. Goulet, M.-A.; Tong, L.; Pollack, D. A.; Tabor, D. P.; Odom, S. A.; Aspuru-Guzik, A.; Kwan, E. E.; Gordon, R. G.; Aziz, M. J., Extending the Lifetime of Organic Flow Batteries via Redox State Management. J. Am. Chem. Soc. 2019, 141 (20), 8014. 29. Badalyan, A.; Stahl, S. S., Cooperative electrocatalytic alcohol oxidation with electron-proton-transfer mediators. Nature 2016, 535, 406.

30. Weiss, C. J.; Wiedner, E. S.; Roberts, J. A. S.; Appel, A. M., Nickel phosphine catalysts with pendant amines for electrocatalytic oxidation of alcohols. Chem. Comm. 2015, $51(28), 6172$.

31. Cheung, K.-C.; Wong, W.-L.; Ma, D.-L.; Lai, T.-S.; Wong, K.-Y., Transition metal complexes as electrocatalysts-Development and applications in electro-oxidation reactions. Coord. Chem. Rev. 2007, 251 (17), 2367.

32. Francke, R.; Little, R. D., Redox catalysis in organic electrosynthesis: basic principles and recent developments. Chem. Soc. Rev. 2014, 43 (8), 2492.

33. Bruce, D. B.; Thomson, R. H., 521. Aromatic keto-enols. Part II. Some new 2 : 3dihydro-1 : 4-naphthaquinones and -anthraquinones. J. Chem. Soc. 1952, 2759.

34. Thomson, R. H., 352. The structure of $\beta$-hydrojuglone and related compounds. Keto;enols of the naphthalene series. J. Chem. Soc. 1950, 1737.

35. Kwabi, D. G.; Lin, K.; Ji, Y.; Kerr, E. F.; Goulet, M.-A.; DePorcellinis, D.; Tabor, D. P.; Pollack, D. A.; Aspuru-Guzik, A.; Gordon, R. G.; Aziz, M. J., Alkaline quinone flow battery with long lifetime at pH 12. Joule 2018, 2, 1907. 